\title{
Çimento Fabrikalarında Alternatif Hammadde ve Yakıt Kullanımı: Örnek Çalışma
}

\author{
Şeyma Ordu1, ${ }^{*}$, Ebru Öztürk ${ }^{2}$ \\ ${ }^{1}$ Namık Kemal Üniversitesi, Çorlu Mühendislik Fakültesi, Çevre Mühendisliği Bölümü, 59860 Çorlu, Tekirdağ.

\section{Özet}

Türk Çimento Sektörü, endüstriyel ve evsel nitelikli atıkları lisansl tesislerinde alternatif yakıt veya hammadde olarak kullanabilmektedir. Alternatif yakıt ve hammadde kullanımının artması çevre kirliliğinin önlenmesi, doğal kaynakların ve enerjinin tasarruf edilmesi açısından oldukça önemlidir. Alternatif yakıtlar genel olarak arıtma çamuru, atık yağ, ömrünü tamamlamış lastikler, solvent ve boya grupları altında toplanabilir. Alternatif hammaddeler ise maden atıklarl, ısıl işlem atıklarl, inşaat atıkları grupları altında değerlendirilebilir. Bu çalışmanın amact, alternatif hammadde ve alternatif yakıt kullanımının ve çevresel yararlarının değerlendirilmesidir. Bu amaçla, örnek olarak seçilen bir çimento tesisinde, 2013-2015 yıllarında kabul edilen atıklar, kabul öncesi yapılan analizler, kullanılan alternatif hammaddelerin ve yakıtların miktarlarl ve maliyete olan etkileri incelenmiștir. Çimento fabrikasında alternatif hammadde olarak demir koku, grid, döküm kumu ve fosfojips, kalite parametrelerine uyumlu bir şekilde geri kazanılmaktadır. Alternatif hammadde kullanımı maliyet olarak tesise toplamda 7.031 .998 TL kazanç sağlamıştır. Alternatif yakıt olarak arıtma çamuru kullanılmaktadır. Arıtma çamuru kullanımının maliyet olarak tesise kazancı 200.514 .450 TL olmuştur.

\section{Anahtar Sözcükler}

Çimento Üretimi, Alternatif Hammadde, Alternatif Yakıt

\section{Alternative Usage of Raw Material and Fuel in Cement Plants: Case Study}

\begin{abstract}
Turkish Cement Sector uses industrial and domestic wastes as alternative fuels or raw materials in licensed facilities. Increasing use of alternative fuels and raw materials is very important in terms of eliminating environmental pollution, saving natural material resources and energy. Alternative fuels can generally be gathered under the groups of sewage sludge, waste oil, worn out tires, solvent and paints. As for alternative raw materials, they can be evaluated undermine waste, heat treatment waste, construction waste groups. The aim of this study is to evaluate the use of alternative raw materials and fuels and their environmental benefits. For this purpose, in a cement plant selected as a case study, wastes accepted between 2013 and 2015, pre-acceptance analyzes, quantities of alternative raw materials and fuels used, and their financial impacts are examined. Iron scent, grid, casting sand and phosphogypsum are recycled as an alternative raw material in the cement plant in accordance with quality parameters. The use of alternative raw materials resulted in savings totaling $7.031 .998 \mathrm{TL}$ for the plant. As alternative fuel, sewage sludge is used. The financial benefit of sewage sludge usage to the plant is 200.514.450 TL.
\end{abstract}

$\underline{\text { Keywords }}$

Cement Production, Alternative Raw Materials, Alternative Fuel

\section{Giriş}

Türkiye, 2013 yılı verileri baz alındığında çimento üretiminde Avrupa'da ilk sırada, Dünyada ise ilk beş arasında bulunmaktadır. Ülkemizde 2013 yılı verilerine göre 100 milyon $\mathrm{m}^{3}$ hazır beton ve 70 milyon ton çimento üretimi yapılmıştır. Bu üretim miktarı çevresel, sosyal ve maliyet artışına bağgl ekonomik sorunlar oluşturmaktadır. Bu nedenle son yıllarda, çimento üretimi sonucu oluşan $\mathrm{CO}_{2}$ emisyonunu azaltmak ve doğal kaynakları daha verimli kullanmak için alternatif yakıt ve alternatif hammadde kullanımı giderek artmaktadır. Alternatif hammadde üretim sonucunda meydana gelen ve mineral özellikleri sebebi ile çimento fabrikalarında hammaddeye katkı olarak kullanılabilir nitelikteki atıktır. Alternatif yakıt ise atıkların 1sıl değer bakımından yararlanılabilir kısımlarından elde edilen yakıttır. Alternatif yakıt ve hammadde kullanımının artması, çevre kirliliğin önlenmesi, doğal hammadde kaynaklarının ve enerjinin tasarruf edilmesi açısından oldukça önemlidir (Engin 2015). Alternatif hammadde olarak başta uçucu kömür külü, yüksek firın cürufu olmak üzere demir, alüminyum ve silis içeren arıtma çamuru ve külleri kullanılabilmektedir. Arıtma çamuru küllerinin bileşimi ve hidrolik özellikleri yapı malzemelerinden çimentoya büyük ölçüde benzemektedir (Yusuf vd. 2012). 
Arıtma çamurunun külü çimento bileşimine çok yakın olduğundan organik kısım yandıktan sonra kalan mineral kısmı çimento içinde kalarak hammadde olarak değerlendirilmektedir. Bunun yanı sıra, bu mineral kısmın kristal kompozisyonu çimento klinkerinin kalitesi üzerinde belirleyici etkiye sahiptir (Alyanak 2014; Xu vd. 2014). Çimentonun hammadde karışımı olan kalsiyum $(\mathrm{Ca})$, silisyum $(\mathrm{Si})$, alüminyum $(\mathrm{Al})$ ve demir $(\mathrm{Fe})$ oksitleri genellikle alternatif yakıtlarında ana bileşenleridir. Çamur çimento firınında birlikte yakılacaksa kireçle stabilizasyon tavsiye edilmektedir. Kireçle stabilize edilmiş ve şartlandırılmış çamur (0.3-0.5 kg CaO/kg kuru çamur) çimentoya yakın bir bileşime sahiptir (Ayvaz 2000).

2014 y1lı verilerine göre ülkemizde faaliyet gösteren 50 çimento fabrikasının 35'inde Çevre ve Şehircilik Bakanlığı'ndan alınan izinler kapsamında, endüstriyel ve evsel atıklar, alternatif yakıt ve alternatif hammadde olarak kullanılmaktadır. Türk çimento sektöründe üretim sürecinde geri kazanılabilen alternatif yakıtlar; atıktan türetilmiş yakıtlar, ahşap, tekstil, plastik gibi bileşenler içeren çeşitli evsel veya endüstriyel atıklar, farklı türlerde uygun 1sıl değere sahip arıtma çamurları, atık yağlar, sintine atıkları, ömrünü tamamlamış lastikler ve solventlerdir. Geri kazanılabilen alternatif hammaddeler ise maden atıkları, ısıl işlem atıkları ve inşaat atıklarıdır. Türk çimento sektörü, Çevre ve Şehircilik Bakanlığı tarafından atık olarak kabul edilen 850'den fazla farklı malzemenin ancak 250 kadarını alternatif yakıt ve alternatif hammadde olarak geri kazanmaktadır. Nükleer atıklar, bulaşıcı tıbbi atıklar, bataryalar ve ön işlemden geçmemiş karışık belediye atıkları gibi malzemelerin çimento sanayinde geri kazanımı mümkün değildir (TÇMB 2014).

Atık kabulünün en önemli aşamalarından biri kabul mekanizmalarının oluşturulmasıdır. Bu amaçla tesisler kabul ettikleri atıklar için prosedürler ve talimatlar oluşturmuştur. Bu prosedür ve talimatlarda atığın tesise kabulü öncesi alınacak bilgilerden, kabul esnasında izlenecek adımlara kadar birçok aşama detayları ile verilmektedir (Ergüçlü 2016). Çimento sektöründe kullanılacak alternatif yakıtların üretim prosesine, ürün kalitesine ve hava kirliliğine etkisinin standartlara uygun ölçüde olması gerekmektedir. Önemli bir kriter de yakıtların 1sıl değeridir. Çimento sektöründe kullanılabilecek alternatif yakıtların 1sıl değerleri Tablo 1'de verilmiştir (Ayhan 2012).

Bu çalışmada amaç, atıkların çimento sektöründe alternatif hammadde ve alternatif yakıt olarak kullanımının örnek olarak seçilen bir çimento fabrikası baz alınarak, nasıl kullanıldığı, izlenilen yöntemler ve maliyete olan etkilerinin araştırılmasıdır.

Tablo 1: Alternatif yakıtların ısıl değerleri (Ayhan 2012)

\begin{tabular}{|l|c|}
\hline Alternatif yakıt & Ortalama isıl değer (kcal/kg) (Petrokok 7500) \\
\hline Ömrünü tamamlamış lastik & 5500 \\
\hline Endüstriyel plastik & 5000 \\
\hline Atık yağlar & 9000 \\
\hline Solventler & 7500 \\
\hline Parçalanmış kağıt & 3400 \\
\hline Yağlı kontamine atıklar & 3500 \\
\hline Bitki kabukları & 4760 \\
\hline Atıktan üretilen yakıt (RDF) & 2800 \\
\hline Arıtma çamuru & 3000 \\
\hline Kontamine atıklar (ambalaj-giysi) & 3000 \\
\hline
\end{tabular}

\section{2. Örnek Olarak Seçilen Çimento Tesisinin Tanıtımı}

İşletme $242.824 \mathrm{~m}^{2}$ yüzölçümlü alan üzerinde, $34.080 \mathrm{~m}^{2}$ yüzölçümlü kapalı alanda yer almaktadır. Tesiste 81 idari personel, 109 işçi 3 vardiya halinde çalışmaktadır. İşletme 1.842 .500 ton/yıl klinker, 2.000 .000 ton/yıl üzerinde üretim kapasitesiyle çimento üretmektedir (Öztürk 2016).

Tesiste kuru sistem ile çimento üretilmektedir ve üretim faaliyetleri 5 ana başlık altında incelenebilir. Bunlar; hammaddenin temini için hammadde ocak işletmeciliği, tesise hammaddenin intikal ettiği ve kırılarak homojene edilmek üzere stoklandığı kırıcılar ve preblending ünitesidir. Bu üniteden alınan hammadde klinker üretim ünitesinde çimentonun yarı mamulü olan klinkere dönüştürülmektedir. Bundan sonra klinker çimento üretim ünitesinde öğütülerek çimentoya dönüştürülmektedir. Elde edilen çimento paketleme ünitesinde paketlenerek veya dökme olarak silolara doldurularak piyasaya satılmaktadır. Şekil 1'de temsili olarak çimento üretim şeması gösterilmiştir. 


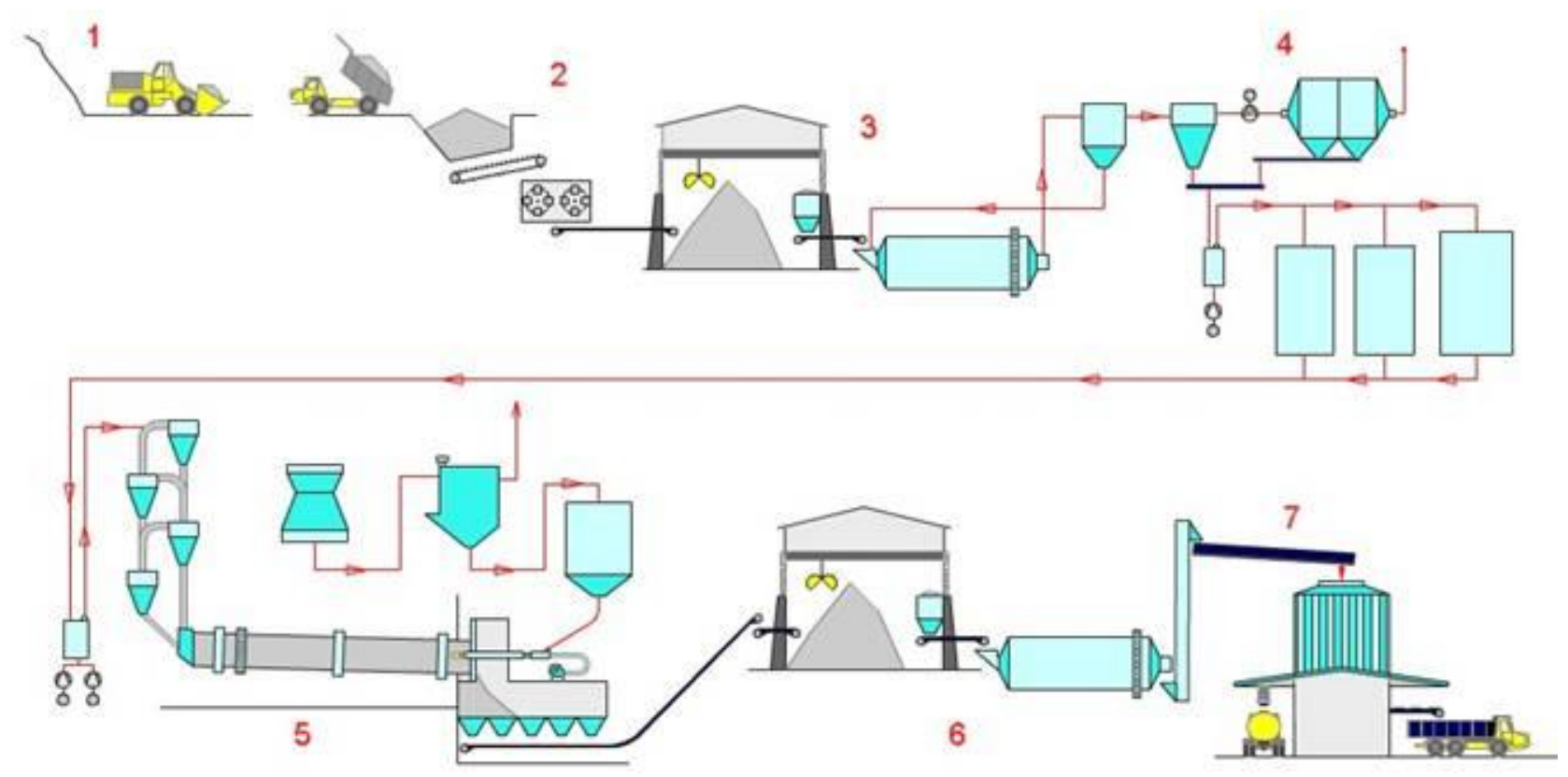

Şekil 1: Çimento üretim şeması (Öztürk 2016).

Hammadde ocaklarında (1) vagon drill ile delme işlemi yapılmakta ve gecikmeli ve exel kapsüllerle patlatma işlemi yapılmaktadır. Çıkan malzemeler kamyonlarla hammadde konkasörlerinde kırılarak (2) preblending ve stokholde stoklanmaktadır. Ocaklarda atıksu oluşumu söz konusu olmayıp, hammadde ocaklarında hava emisyon kaynağı bulunmamaktadır. Çimento imalatı amacıyla hammaddelerin kırılması gerekmektedir. Malzemeler genelde $1.5 \mathrm{~m}$ boyutundadır. İyi kalitede klinker eldesi için malzeme en az $0.2 \mathrm{~mm}$ boyutuna kırılmalıdır. Kırılan malzemeler stok alanında bekletilmekte (3) ya da farin değirmenine gönderilmektedir. Ham karışım hammadde stokholünden ve tehlikesiz atıkların ilavesi ile birlikte farin değirmenine beslenmektedir (4). Burada öğ̈̈ülen farin, farin stok silosunda depolanmaktadır. Farin stok silosundan alınan farin klinker üretim hattının ön 1sitıcı siklonlarına beslenmektedir. Ön 1sıtıcı aşamasında kalsinasyonu tamamlanan farin döner firına intikal etmektedir. Burada meydana gelen kilinkerleşme reaksiyonları neticesinde oluşan malzeme klinker soğutma ünitesine dökülerek hava marifeti ile soğutulmaktadır ve klinker stok silosuna sevk edilmektedir. Kömür değirmeninde öğütülen kömür, daha sonra döner firında yakıt olarak kullanılmaktadır.

Çimento öğütmek için kullanılan değirmen, boru değirmendir. Boru değirmenler, farklı düzeneklerle döndürülen, aşınmayı önlemek için içleri plakalarla kaplanmış silindirlerdir. Değirmende öğütmeyi sağlamak için çelik bilyeler ve/veya silpeps adı verilen silindirik çelik malzemeler kullanılmaktadır. Tesiste çimento değirmeni öncesinde 5 adet bunker, altında tartım kantarları ile birlikte yer almaktadır. Bunlardan klinker bunkeri 800 ton, diğerleri ise 400 tonluktur ve bu klinker ve katkı bunkerlerinden isteğe bağlı çimento oranları belirlenir ve değirmenlere besleme yapılır (5). Çimento değirmenleri bilyeli değirmenlerdir ve öğütme işlemi farklı boyutlardaki bilyelerle yapılmaktadır. Tesis bünyesinde 2 adet değirmen bulunmaktadır. İkinci değirmende karışım değirmene gitmeden önce ön eziciden geçirilmektedir. Değirmenlerden geçen çimento istenilen inceliğe ulaşabilmesi için diğer kapalı öğütme ünitelerinde olduğu gibi seperatöre girmekte (6) ve ince malzeme filtrede tutulup silolara gönderilirken, kalın malzeme değirmene geri sevk edilmektedir. Öğütülmüş ve uygun kalitede çimento tipleri 10.000 ve 11.000 ton kapasiteli olan 2 siloda depolanmaktadır (7). Çimento satışa torbalı ve açık (dökme) olarak sunulmaktadır. Dökme hattında sevkiyatı yapacak olan silobus kamyon dökme hattı peronuna, torbalı alım yapacak kamyon ise torbalı sevkiyat peronuna yanaşarak yüklemeyi yapmaktadır. Araç yüklemeleri tamamlandıktan sonra kantarda tartılarak çıkış verilmektedir (Öztürk 2016).

Fabrikaya atıklar gelmeden önce, atığını göndermek isteyen firma ile görüşülerek atık hakkında bilgi alınmaktadır. Atık Yönetimi Genel Esaslarına İlişkin Yönetmelik kapsamında atığın özellikleri belirlenmişse, atık üreticisinden analiz raporları alınmaktadır. Tesise atık üreticisinin sorumluluğu ve organizasyonu altında, lisanslı araçlarla gelen atıklardan numune alınmakta ve Kalite Kontrol Laboratuvarında su (rutubet) içeriği, kalorifik değeri analizleri yapılmakta ve klor, flor, ağır metal içeriği gibi analizler ise fabrikada veya anlaşmalı akredite laboratuvarda yaptırılmaktadır. Kabul edilen atıklar tür ve özelliklerine göre atık stok sahasında ayrı ayrı bölmelerde depolanmaktadır. Ulusal Atık Taşıma Formu düzenlenmeyen atıkların tesise girişine izin verilmemektedir.

Atık yakma birlikte yakma işleminde kullanılacak atıkların stoklanması için işletmede $325 \mathrm{~m}^{2}$ büyüklüğünde kapalı alan yer almaktadır. Bu ünitelerde atık kabulü, atığın içerisinde radyoaktif madde bulunup bulunmadığı, depolanması, atıkların hazırlanması, atıkların yakma için taşınması işlemleri gerçekleştirilmektedir. 
Atıklar döner fırında yakılmadan önce, yakma şartlarına göre hazırlanmaktadır. Döner firına atıklar, fırın ana alev borusundan ve kalsinatörden beslenmektedir. Döner firın ana bacasında yanma gazı emisyonları takip edilmekte ve ayrıca lisans şartları gereği belirlenen periyotlarda gaz, toz, özel madde, ağır metal, dioksin ve furan ölçümleri Çevre ve Şehircilik Bakanlığı tarafından yetki verilen akredite laboratuvarlar tarafından ölçülerek raporlanmaktadır (Öztürk 2016).

\subsection{Alternatif hammaddelerin tesise kabulü, hazırlanması ve kullanılması}

Alternatif hammadde olarak kullanılan atıkların tesise kabulü "Alternatif Hammaddelerin Kabulü ve Kullanım Talimatı" kapsamında yapılmaktadır. Talimat kapsamı;

- Tedarikçi firma ile görüşme ve atık numunesi istenmesi,

- Atık numunesi analiz sonucuna göre yetkili kişiler tarafından atığın alınıp alınamayacağına karar verilmesi,

- Firmaya fiyat gönderilmesi aşaması ve sözleşme imzalanması,

- Atığın tesise kabulü ve laboratuvar tarafından gerekli analizlerin yapılmasıdır

Kabulü yapılan alternatif hammaddeler; sızdırmazlığı sağlanmış, etrafı çevrili, görevli personel harici kişilerin girişi engellenen, yağmur ve yüzey sularının drenajı için gerekli tedbirler alınmış olan, tehlikesiz atık stok alanında depolanmakta ve iş makinaları ile hammadde veya çimento katkıları içerisine nakledilmektedir.

\subsection{Alternatif hammaddeler için yapılan analizler}

Alternatif hammaddeler tesiste kullanılmadan önce, tesisin laboratuvarında kimyasal analize tabi tutulmaktadır. Döküm Kumu, çimentoda silis kaynağı olarak kullanılmaktadır. Döküm kumuna kimyasal analiz yapılmaktadır. Analizde bakılan parametreler; $\mathrm{SiO}_{2}, \mathrm{Al}_{2} \mathrm{O}_{3}, \mathrm{Fe}_{2} \mathrm{O}_{3}$ ve nem oranıdır. Nem oranı düşük olması gerekmektedir.

Demir Koku ve Grid atıkları çimentoda demir cevheri yerine kullanılmaktadır. Bunlara kimyasal analiz yapılmaktadır. Analizde bakılan parametreler; $\mathrm{Fe}_{2} \mathrm{O}_{3}, \mathrm{SiO}_{2}, \mathrm{Al}_{2} \mathrm{O}_{3}$, ve nem oranıdır. Nem oranı düşük olması gerekmektedir.

Alçı Atıkları ve Fosfojips, çimentoda $\mathrm{SO}_{3}$ kaynağı olarak kullanılmaktadır. Bunlara kimyasal analiz yapılmaktadır. Analizde bakılan parametreler; $\mathrm{SO}_{3}$ ve nem oranıdır. Nem oranı düşük olması gerekmektedir.

Arıtma Çamuru ve Baca Tozu, çimentoda silis kaynağı olarak kullanılmaktadır. Bunlara kimyasal analiz yapılmaktadır. Analizde bakılan parametreler; $\mathrm{SiO}_{2}, \mathrm{Al}_{2} \mathrm{O}_{3}, \mathrm{Fe}_{2} \mathrm{O}_{3}$ ve nem oranıdır. Nem oranı düşük olması gerekmektedir (Öztürk 2016).

\subsection{Alternatif yakıtların tesise kabulü, hazırlanması ve kullanılması}

Alternatif yakıt olarak kullanılan atıkların tesise kabulü “Alternatif Yakıtların Kabulü Talimatı” kapsamında yapılmaktadır. Talimat kapsamı;

- Tedarikçi firma ile görüşme ve atık numunesi istenmesi,

- Atık numunesi analiz sonucuna göre yetkili kişiler tarafından atığın alınıp alınamayacağına karar verilmesi,

- Firmaya fiyat gönderilmesi aşaması ve sözleşme imzalanması,

- Atığın tesise kabulü ve laboratuvar tarafindan gerekli analizlerin yapılmasıdır.

Kabulü yapılan alternatif yakıtlar Geçici Atık Depolama Sahasında bekletilmektedir. Bu sahanın özellikleri şöyledir:

- Geçici Atık Depolama Sahasına alınacak atıklar, doğru tasnif edilip stoklanmaları için birbirine karışmayacak şekilde boşaltılmaktadır.

- Bu sahada ilgili atıklar haricinde başka atık ve malzemeler depolanmamaktadır (tıbbi atıklar, metal malzemeler gibi).

- Atığın özelliğini, kimyasal ve fiziksel yapısını olumsuz olarak etkileyebilecek çevre, iklim vb. koşullardan atığı koruyacak gerekli tedbirler alınarak depolama yapılmaktadır. Rutubetinin artmaması için yağmur suları ile temasının olmaması için tedbirler alınmaktadır.

- Depolama sahası tanımlı olup, gerekli uyarı levhaları bulunmaktadır.

- Arıtma çamuru (kuru), kamyonlarla arıtma çamuru silosuna basılarak oradan otomatik olarak yakıt olarak kullanılmaktadır.

\subsection{Atık hazırlama işlemleri}

Atık hazırlama işlemleri “Atıkların Yakma İçin Hazırlanması ve Yakılması Talimatı” kapsamında yapılmaktadır. Talimat kapsami;

- Gelen atıkların geçici atık depolama sahasına alınması,

- Laboratuvar tarafından gerekli analizlerin yapılması,

- Analiz sonuçlarının uygunluğuna göre ve gelen atığın atık klapesinden geçme büyüklüğünün uygun olması halinde atık beslemesinin yapılmasıdır (Öztürk 2016). 


\subsection{Alternatif yakıtlar için yapılan analizler}

Alternatif yakıtlar tesiste kullanılmadan önce, tesisin laboratuarında kalorifik analizlere tabi tutulmaktadır. Sadece arıtma çamuruna kimyasal analiz de yapılmaktadır. Kimyasal analizde bakılan parametreler $\mathrm{SiO}_{2}$ ve nem oranıdır. Nem oranı \%90-95 kurulukta olmalıdır. Tesise kabul edilen alternatif yakıtlara uygulanan kalorifik analiz sonucu istenilen kalori değerleri Tablo 2'de gösterilmiştir.

Tablo 2: Tesise kabul edilen alternatif yakıtların ortalama kalorisi

\begin{tabular}{|l|c|}
\hline Alternatif yakıt & Ortalama kalori (kcal/kg) \\
\hline Arıtma çamuru & $2500-3000$ \\
\hline Kontamine atık & $3000-3500$ \\
\hline Atık lastik & $5000-5500$ \\
\hline Tekstil ürünü atıkları & $2000-3000$ \\
\hline Atık yağ & $8000-9000$ \\
\hline
\end{tabular}

\section{Tesise Kabul Edilen Alternatif Yakıt ve Alternatif Hammaddelerin Kullanım Durumları}

Petrokok ve Kuru Arıtma Çamuru Karşılaştırılması: Yakıt ikamesi olarak tesiste 2015 yılında 9.062,800 ton arıtma çamuru kullanılmıştır. Arıtma çamurunun kalorisi $2100 \mathrm{kcal} / \mathrm{kg}$ 'dır. Tesiste arıtma çamuru yerine kalorisi $8000 \mathrm{kcal} / \mathrm{kg}$ olan petrokok kullanılsayd1 2.378,985 ton petrokok kullanılacaktı. Bununda maliyet olarak tesise kazanc1 200.514,450 TL olacaktır.

Kontamine atık: Tesiste 2013 yılında deneme yakması aşamalarında 22,35 ton kontamine atık kullanılmıştır. Tesisin atık besleme ünitesi otomatik olmadığından kontamine atık kullanılmamaktadır.

Ömrünü tamamlamış lastik: Tesiste 2013 yılında deneme yakması aşamalarında 35,35 ton ömrünü tamamlamış lastik kullanılmıştır. Tesisin atık besleme ünitesi otomatik olmadığından ömrünü tamamlamış lastik kullanılmamaktadır.

Atık yağ: Tesiste 2013 yılında 356,45 ton, 2014 yılında 155,70 ton atık yağ kullanılmıştır. Atık yağ alınan firmaların farklı sektörlere atık yă vermesi ve pazar bulunamaması nedeniyle kullanılmamaktadır.

Tekstil ürünleri: Tesiste 2013 yılında deneme yakması aşamalarında 13,95 ton tekstil ürünleri kullanılmıştır. Tesisin atık besleme ünitesi otomatik olmadığından tekstil ürünleri kullanılmamaktadır (Öztürk 2016).

Demir Cevheri ve Grid Karşılaştırması: 2015 yılında tesiste 18.700 ton grid kullanılmıştır. Demir içeriği ortalama 47,68 $\mathrm{Fe}_{2} \mathrm{O}_{3}$ 'tür. Tesiste ortalama 41,29 $\mathrm{Fe}_{2} \mathrm{O}_{3}$ demir içerikli demir cevheri kullanılsayd1, 21.593 ton demir cevheri kullanılacaktı. Bununda maliyet olarak tesise kazanc1 1.036.673 TL olacaktır.

Demir Cevheri ve Demir Koku Karşılaştırması: 2015 yılında tesiste 121.000 ton demir koku kullanılmıştır. Demir içeriği ortalama 45,45 $\mathrm{Fe}_{2} \mathrm{O}_{3}$ 'tür. Tesiste ortalama 41,29 $\mathrm{Fe}_{2} \mathrm{O}_{3}$ demir içerikli demir cevheri kullanılsayd1, 133.191 ton demir cevheri kullanılacaktı. Bununda maliyet olarak tesise kazanc1 4.797.151 TL'dir.

Silis Kumu ve Döküm Kumu Karşılaştırması: 2014 yılında tesiste 12.433 ton döküm kumu kullanılmıştır. Silis içeriği ortalama $64,41 \mathrm{SiO}_{2}$ 'dir. Tesiste ortalama $80,20 \mathrm{SiO}_{2}$ silis içerikli silis kumu kullanılsaydı 9.985 ton silis kumu kullanılacaktı. Maliyet olarak tesise kazancı 113.829 TL'dir. Ancak döküm kumunun uzun süreli kullanımında 28 günlük klinker mukavemetlerinde olumsuz etkisi görülmüştür. Ayrıca değişken kimyasal içeriğinden dolayı, hammadde harmanında sadeleştirmeye gidilmesi ve stabilitenin sağlanması için kullanımı azaltılarak durdurulmuştur.

Alçı ve Fosfojips Karşılaştırması: 2014 yılında tesiste 65.130 ton fosfojips kullanılmıştır. $\mathrm{SO}_{3}$ içeriği ortalama 46,18 $\mathrm{SO}_{3}$ 'dir. Bunun yerine ortalama 40,35 $\mathrm{SO}_{3}$ içerikli alçı kullanılsaydı 74.540 ton alçı kullanılacaktı. Maliyet olarak tesise kazancı 1.084.345 TL'dir. Tesiste maksimum \%20 oranında fosfojips kullanılmaktadır. Asidik içeriğinden dolayı alçıdan azaltılarak kullanılmaktadır. Ayrıca çimentonun donma süresine etki ederek kalite değerlerine olumsuz etkileri olmaktadır.

Arıtma Çamuru: Hammadde olarak tesiste arıtma çamuru (\%60-70 nemli) 2014 yılında 11.646,75 ton kullanılmıştır. Fakat 2015 yılında azaltılarak 231,25 ton kullanılmıştır. Hammadde harmanında sadeleştirmeye gidilmesi ve stabilitenin sağlanması için kullanımı azaltılarak durdurulmuştur.

Baca Tozu: Tesiste baca tozu 2014 yılında 4.310,10 ton kullanılmıştır. Fakat 2015 yılında azaltılarak 595,35 ton kullanılmıştır. Değişken kimyasal içeriğinden dolayı, hammadde harmanında sadeleştirmeye gidilmesi ve stabilitenin sağlanması için kullanımı azaltılarak durdurulmuştur (Öztürk 2016).

\section{Sonuçlar}

Atıkların çimento fabrikalarında kullanılması, birincil yakıt ve hammaddelerin, kabul kriterlerine uygun atıklar ile ikame edilmesi işlemidir. Alternatif yakıt ve alternatif hammadde olarak kullanılan atıkların 1sıl değeri veya malzeme değeri çimento fabrikalarında geri kazanılmaktadır. Alternatif yakıtların kullanılması fosil yakıtlara bağımlılığın 
azaltılması ve bu yakıtlardan kaynaklanan hava kirletici emisyonların azaltılmasına katkıda bulunmaktadır. Makale çalışmasında seçilen örnek tesiste alternatif hammadde ve alternatif yakıt alım ve kullanım işlemleri yönetmelikler ve lisansı çerçevesinde yapılmaktadır. Alınan alternatif hammaddeler çimentonun hammadde reçetesine eklenerek kalite parametrelerine uyumlu bir şekilde geri kazanılmaktadır. Bu şekilde alternatif hammadde kullanılarak fabrikanın atık problemi çözülmekte ve doğal kaynakların kullanımı yerine atık olan malzemeler kullanılmaktadır. Bununla birlikte $\mathrm{CO}_{2}$ salınımının azalması sağlanmakta ve doğal kaynakların azalması bir ölçüde önlenmektedir.

Makale çalışmasında seçilen örnek tesise alınan alternatif hammaddeler olan demir koku, grid, döküm kumu ve fosfojips çimentonun hammadde reçetesine eklenerek, kalite parametrelerine uyumlu bir şekilde geri kazanılmaktadır. Bu alternatif hammadde kullanımı 2014 ve 2015 yıllarına bakıldığında, maliyet olarak tesise toplamda 7.031.998 TL kazanç sağlamıştır. Alternatif hammadde olarak kullanılabilen arıtma çamuru ve baca tozu atıklarının ise çimento üretiminde stabilitenin sağlanabilmesi için alımı yapılmamaktadır. Alternatif yakıt olarak tesiste kuru arıtma çamuru kullanılmaktadır. Kuru arıtma çamurunun kalorisinin 2500-3000 kcal/kg ve \%90-95 kurulukta olması gerekmektedir. 2015 yılı verilerine göre, arıtma çamuru kullanımının maliyet olarak tesise kazanı 200.514.450 TL'dır. Diğer alternatif yakıt olarak kullanılabilen kontamine atıklar, ömrünü tamamlamış lastikler, atık yağlar ve tekstil ürünleri tesiste otomatik besleme sistemi olmadığından alınmamaktadır.

\section{Kaynaklar}

Alyanak İ., (2014), Atıksu çamurlarının değerlendirilmesiyle ilgili Türkiye'deki uygulamalar, 4. Turkish-German Water Partnership Day, 23-24 Eylül, Antalya.

Ayhan S., (2012), Çimento sektöründe atıktan enerji geri kazanımı ve yasal mevzuat, 18th International Energy and Environmental Fair and Conference, 25-27 Nisan, İstanbul.

Ayvaz, Z., (2000), Atıksu arıtma çamurlarının değerlendirilmesi, Ekoloji ve Çevre Dergisi, 9(35), 3-12.

Engin Y., (2015), Çimento endüstrisinde sürdürülebilirlik, http://www.betonvecimento.com/wp-content/uploads/2015/02/çimentoüretiminde-sürdürülebilirlik.pdf, [Erişim 10 Kasım 2015].

Ergüçlü M E., (2015), Çimento fabrikalarında ek yakıt kullanımı, http://www.bke.com.tr/son-haberler/cimento-fabrikalarinda-ekyakit-kullanimi.html [Erişim 20 Nisan 2016].

Öztürk E., (2016), Çimento sektöründe alternatif hammadde ve alternatif yakıt kullanımının çevresel yararlarının değerlendirilmesi, Yüksek Lisans Tezi, Namık Kemal Üniversitesi, Tekirdağ.

TÇMB, (2014), Türk çimento sektörünün alternatif yakıt ve alternatif hammadde kullanımı yaklaşımı, Türkiye Çimento Müstahsilleri Birliği, http://www.tcma.org.tr/images/file/Turk_cimento_sektorunun_alternatif_yakit_hammadde_kullanim_yaklasimi_Kasim_ 2014.pdf, [Erişim 20 Nisan 2016].

Xu W., Xu J., Liu J., Li H., Cao B., Huang X., Li G., (2014), The utilization of lime-dried sludge as resource for producing cement, Journal of Cleaner Production, 83, 286-293.

Yusuf R.O., Noor Z.Z., Din M.D., Abba A.H., (2012), Use of sewage sludge ash (ssa) in the production of cement and concrete-a review, Int. J. Glob. Environ., 12, 214-228. 